\title{
Annales Henri Lebesgue
}

Xavier Caruso (Université de Rennes, France), Dominique Cerveau (Université de Rennes, France), Sébastien Gouëzel (Université de Nantes, France), Xhensila Lachambre (Université de Rennes, France), Nicolas Raymond (Université de Rennes, France) and San Vũ Ngọc (Université de Rennes, France)

Translated from the French La Gazette des Mathématiciens 155 by P.D. Hislop (University of Kentucky, Lexington, KY, USA), with the authorisation of the Gazette.

\section{Of fleeting and eternal mathematics}

Mathematical theorems, their proofs and ideas that give them life do not belong to anyone, not even their authors. Upon writing this, one can easily imagine the small smile appearing on the mouth of the reader, as if to betray the beginning of a small resistance to this statement. These somewhat exaggerated statements, however, are able to open the way to reflection. It is in the same way that from an indistinguishable block of stone, certain sculptors of Antiquity were able to carve beautiful and graceful figures rivalling nature. One has to mention the story of a certain Cypriot Pygmalion, who created such a lifelike sculpture and who loved it with such passion that Venus gave her life. ${ }^{1}$ There are also many legends in which men assume the character of demiurges, ${ }^{2}$ who give life to shapeless and inert objects. We remember, for example, the wise men Deucalion and Pyrrha, saved from the flood by Jupiter, who recreated humanity by throwing stones (probably clay stones) behind them. ${ }^{3}$

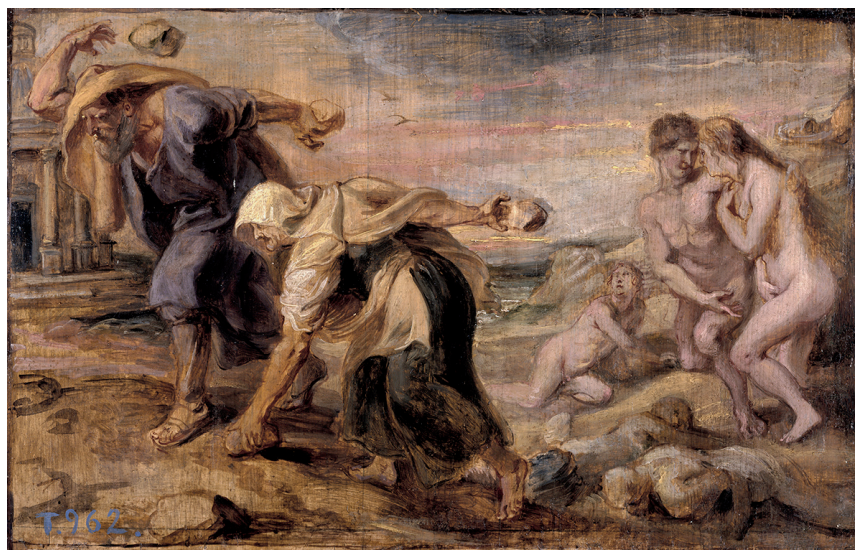

Deucalion and Pyrrha, Rubens (1636), Prado Museum.

Beyond the symbolism of these stories, it is in clay that the first mathematical calculations and the first recitation of these myths (Eastern and Western) were written, as if the authors were like the artisans and mythical creators. Of course, the Ancients not only wrote on tablets: the texts from Antiquity mention that the geometers drew their figures on sand in order to remember their reason-

\footnotetext{
1 Ovid: Metamorphoses, Book X, 243.

2 From the Greek $\delta \varepsilon \mu o \zeta$ (people) and $\varepsilon \rho \gamma o v$ (work): originally meaning artisan, now creator.

3 Ovid: Metamorphoses, Book I, 325.
}

ing and to transmit their ideas to future generations. In this manner, Socrates led a slave to publicly solve the problem of the duplication of a square. ${ }^{4}$ But, dear reader, perhaps you did not choose to read this article in order that we snare you in Ovid's Metamorphoses or tell you about Platonic reminiscences. What remains of the sand that anchored the geometers' arguments in the moment or of the clay tablets of the scribes that were supposed to preserve their works?

\section{A giant with feet of clay ${ }^{5}$}

A little in the Platonic spirit that, worn down by time, joins desire and forgetfulness, let's leave antiquity and together leap over the centuries to the present. Chalk replaced sand and university amphitheatres and specialised schools welcome assemblies of students. Classes and recitations, at the core so fleeting, fight regularly against the forgetfulness and safeguard the fabulous sum of knowledge acquired since Antiquity. This knowledge calls for our responsibility: the question of scientific memory and its diffusion is urgent. But what has become of the clay tablets? Not so long ago, works of mathematics were exclusively published on paper. Perhaps, dear reader, you yourself have lingered in mathematics libraries and wandered from aisle to aisle in search of some elusive mathematical theorem? Perhaps you have sat in a comfortable chair, an article in one hand and a pen in the other, secretly charmed by this precious pleasure? Little by little, mathematical works have been digitalised. From now on, these works haunt many public and private servers; they are immediately accessible and are no longer weighed down by paper. Of course, they have not become pure spirits and printing them has not yet become a spiritual endeavour. They are still material and most of them are lodged in the servers of the commercial publishers that, by convention, we'll call Elsa and Sponz.

This commercialisation exerts a continuous financial pressure on public institutions (laboratories, research centres, universities, etc.) serving science. Elsa and Sponz only care about the preservation of knowledge as an afterthought: they decide our needs to satisfy theirs. In this way, access to works of mathematics is not only for a fee. It is also submitted, for example, to the rule of the bouquet of journals: in order to access one journal, we must also access a collection of other journals that we might not desire. A research centre might want a bouquet of roses and tulips but the obscure florists require it to add some daisies, dandelions and, sometimes, an entire

\footnotetext{
4 Plato: Meno, $80 \mathrm{~d}$.

5 Book of Daniel, verses 2.31-2.45, Bible.
} 
haystack. Where is the scientific coherence in that strategy ${ }^{6}$ The more that we consider these practices normal, the less we find them astounding and, all the while, we see considerable sums of money leave the budgets of research centres each year.

\section{The birth of the Annales Henri Lebesgue}

Despite the fact that many colleagues regret this situation, many don't know how to change these publishing practices. They remark, however, that the authors of many of these articles are very often financed by public research agencies and that the editors and referees donate their work for free. How can one imagine that the fruits of this work are the source of private profits when the fruits depend on the public funds that finance the authors, editors and referees?

This question is all the more gripping when public means of distribution and conservation are readily available for mathematics articles. The recently-founded Centre Mersenne ${ }^{7}$ is, in effect, able to furnish all the services necessary for the publication of mathematics articles: establishing a website for the journal, standardisation, distribution and archiving of articles. To summarise: this can be done with public funds and for far less cost.

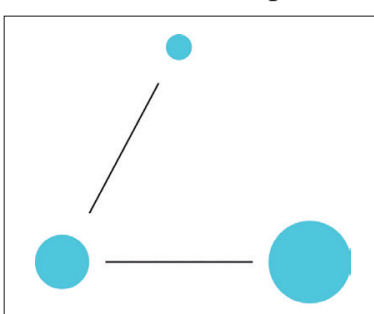

It is in this context that the Annales Henri Lebesgue came to life. For more than two years, researchers in the west of France have worked to create the journal. In the beginning, to be honest, the Annales was only a vague ANNALES HENRI LEBESGUE and elusive idea. However, the sentiment that these ideas incarnate: open access, free publication and high standards, led them to return to these conversations with new vigour. The Centre Henri Lebesgue $^{8}$ aided in nourishing these ideas, moulding them and giving them structure.

Several colleagues have been contacted in order to constitute a strong and motivated editorial board. These colleagues were enthusiastic to participate in this community movement of mathematicians, supported by the Centre National de la Recherche Scientifique. The positive responses were overwhelming and there was a fear there would be too many editors! Zealous colleagues installed the Open Journals Systems ${ }^{9}$ and adapted it to the needs of a mathematics journal. The new journal was legally registered and a graphic artist designed a website for article submission. The Annales Henri Lebesgue ${ }^{10}$ became a real and independent journal.

\footnotetext{
6 One may consult the article by F. Hélein (La Gazette des Mathématiciens 147) in which the author considers this question.

7 The Centre Mersenne provides comprehensive scientific publishing infrastructure, and is a joint project of the CNRS and Université Grenoble Alpes: http://www.centre-mersenne. org/en/mersenne/

$8 \mathrm{https}: / /$ www.lebesgue.fr/fr

9 https://pkp.sfu.ca/ojs/.

${ }^{10} \mathrm{https} / / /$ annales.lebesgue.fr/index.php/AHL/.
}

\section{Readership and editorial committee}

The Annales Henri Lebesgue is a general mathematics journal, completely electronic, that strives to publish high-quality articles. It is freely accessible to all. Although the initiative was born in the west of France, the diverse editorial committee represents many fields of mathematics. Roughly half of the committee is composed of mathematicians from other regions, the majority of whom are foreigners. Of course, this new journal will not resolve all the problems of for-profit publishing by itself. It will join the collection of mathematics journals that have reasonable publishing practices. ${ }^{11}$ The editorial committee will be renewed regularly in order to both involve other mathematicians as well as to cover, over time, a large spectrum of mathematical fields, taking into account the broadness of mathematics.

\section{Publish your papers in a free-access journal!}

The Annales Henri Lebesgue is accessible and open to all, from advanced graduate students to experienced researchers. Many might hesitate to send a good paper to a newly-established journal whose reputation is not yet fully established. One might wonder if papers published in this journal will enjoy immediate recognition. One would be surprised, however, by the growing enthusiasm of mathematicians, especially young mathematicians, for these editorial initiatives and by their desire to be associated with the journal and these initiatives. In creating this journal, we are responding to this desire in offering them a journal worthy of their best papers. So, it is without hesitation and with enthusiasm that we ask mathematicians to give life to the Annales Henri Lebesgue.

In fact, good reputations, for the most part, do not spring from the thigh of Jupiter: it is necessary to attract high-quality works and important that a serious editorial board is open to their evaluation. The research papers, in a certain sense, are more important than the journals themselves. Quality papers do not need journals to be well-written or to have an important scientific value. On the other hand, they need the care of the editorial board and quality referees. It is the work of these people who make, over time, the reputation of the journal. This idea has been key in the discussions around the creation of the Annales Henri Lebesgue.

Mathematicians have the means to supervise the totality of the publication process and to participate in a coherent editorial policy. The Annales Henri Lebesgue are among the clay stones that we wish to leave behind us. Contribute to giving them life!

Xavier Caruso [xavier.caruso@normalesup.org] works at the Mathematic Institute of Rennes (IRMAR), France. His field of interest is number theory and especially $\mathrm{p}$-adic numbers (specifically p-adic Galois representations and explicit computations with p-adic objects).

\footnotetext{
${ }^{11}$ Non-exhaustive lists may be found at http://cedram.org/ or http://www.emsph.org/journals/journals.php.
} 
Dominique Cerveau [dominique.cerveau@univ-rennes1. fr] works at the University of Rennes, France. His research topics concern complex geometry and holomorphic foliations. He is the Chief Editor of the Annales Henri Lebesgue.

Sébastien Gouëzel [sebastien.gouezel@univ-nantes.fr] works at the Jean Leray Institute (Nantes), France. His research focuses on the interactions between dynamical systems and probability theory.

Xhensila Lachambre [xhensila.lachambre@univ-rennes1. fr] works at the Mathematics Institute of Rennes (IR-
MAR), France. She is the Editorial Secretary of the Annales Henri Lebesgue.

Nicolas Raymond [nicolas.raymond@univ-rennes1.fr] works at the Mathematics Institute of Rennes (IRMAR), France. His research focuses on semiclassical spectral theory with magnetic fields.

SanVũ Ngoc [san.vu-ngoc@univ-rennes1.fr]works at the Mathematic Institute of Rennes (IRMAR), France. He is interested in microlocal analysis, symplectic geometry, integrable systems and mathematical physics. 